\title{
Socioeconomic Contexts and Teachers' Evaluation Practices in Beninese Secondary Schools: Exploring Efl Teachers' Perspectives
}

\author{
Jean-Marc Gnonlonfoun
}

Gri-digest/larpet/enset/unstim-a

DOI: $10.36348 /$ sjhss.2020.v05i04.002

| Received: 27.03.2020 | Accepted: 04.04.2020 | Published: 10.04.2020

*Corresponding author: Jean-Marc Gnonlonfoun

\section{Abstract}

There are limited data available on how the socio-economic neighborhood of a secondary school affect teachers' beliefs about evaluation and how they influence both the teaching and learning processes in secondary schools. This this research is set out to explore such an issue through a qualitative study of a phenomenographic nature. 24 participants were selected from twelve secondary schools situated in both favorable (urban) and challenging (rural) contexts throughout the country. The findings show that the beliefs of teachers working in challenging contexts have elements of a more inclusive evaluation, more adapted to all students, while teachers from schools in more favorable settings are more demanding, seeking more excellence. Therefore, adaptation to the context is the rule since it is the context that is determining the type of evaluation.

Keywords: Evaluation practices, beliefs, EFL teachers, justice, Benin context.

Copyright @ 2020: This is an open-access article distributed under the terms of the Creative Commons Attribution license which permits unrestricted use, distribution, and reproduction in any medium for non-commercial use (NonCommercial, or CC-BY-NC) provided the original author and source are credited.

\section{INTRODUCTION}

In the literature, there are indications of a growing trend of a research that seeks to investigate teachers' conceptions towards evaluative practice [1-5]. The basic underlying idea is that since beliefs are the first step to action, it is only by changing these conceptions that practices can be improved and, with it, the development of students [6].

Indeed, every human being, by nature, builds ideas, thoughts and judgments on and from his own experiences. This leads him to conceive of the world in a different way from the others, and that affects, in one way or another, his way of acting in the different areas of life. It is clear that the cause of an action is not necessarily a reflection of how a person thinks or conceives of the world, but it certainly determines it in an important way. For example, a teacher evaluating in a certain way does not necessarily reflect what they think is the most appropriate, but it is undoubtedly affected by these implicit ideas. In any case, the way in which the teacher conceives of the evaluation impacts on their own evaluative practice and, therefore, on the teaching-learning process [7].

On the other hand, there is a good amount of evidence that indicates that the socio-economic context in which the school is determines the way in which teachers act. Thus, the research of Lupton [8] where he studied how the social context influences the dynamics of the school is of special interest. The approach was simple; he selected schools in the poorest neighborhoods in England and analyzed how the context marked the work of teachers and managers. And he realized that teachers could not carry out their homework normally, even if they wanted to. They knew the theory and believed they were good teachers, but they could not maintain a good climate, organize structured lessons, propose challenging activities or attend to diversity ... if they had to maintain survival routines such as order in the classroom. Linking both ideas, the following research question is worded: Does the socio-economic context of the school affect teachers' conceptions of evaluative practice? As such, this research aims to delve into the conceptions of evaluation of EFL teachers, and determine if the socioeconomic context of the secondary school in which they work determines differences in conceptions.

\section{REVIEW OF THE LITERATURE}

Pajares [9] stated that paying attention to teachers' conceptions should be a priority topic for educational research. If the concepts determine the behavior of teachers, only knowing them, it is possible to modify them to improve the teaching and 
development of students. Indeed, conceptions are defined as an organized system of beliefs, originated in the experiences of the individual and developed through the interactions in which he participates [5]. It is important to point out that, despite the individualistic appearance, conceptions have a social character, since they are based and interrelated in culturally shared phenomena [10]. Since these beliefs are developed through the personal experiences of individuals, researchers conclude that conceptions are pervasive, and influence and are influenced by the individual's interactions with the world. Thus, a conception is a mental construction on what a subject interprets lives and understands a reality, but in no case how he experiences it since the interest of the conceptions lies in knowing what a subject thinks about a certain process [11].

Teaching conceptions would be, therefore, a framework or structure of beliefs through which teachers interpret and interact day by day in the classroom [12, 13]. Thus, teachers' conceptions are influenced by the context in which the teachers develop, and define their teaching practice. It is clear that this influence is not always coherent or explicit, but conceptions are undoubtedly a decisive factor that determines the teaching-learning process [2].

Prieto and Contreras [14] insist on specifying that teachers do not construct their beliefs intentionally and consciously. On the contrary, they have unconsciously internalized them in their cognitive and emotional structures, based on a great diversity of personal and school experiences. School experiences in the context in which they perform have facilitated the social construction of beliefs regarding education, teaching, learning or evaluation.

In this way, it is not surprising that the study of teachers' conceptions has become a fruitful line of educational research [15]. Within it, the study of teaching conceptions about their evaluative practices is especially relevant [16-25].

The influence of beliefs on the evaluative practice of the teacher is clear: the way in which the teachers conceive the evaluation has direct repercussions on the evaluative practices of the teacher and these on the learning of the students. Indeed, any evaluation carried out by a teacher exercises a determining power in both pedagogical practices and student learning [26, 14].

In recent years, and especially from Brown's work $[18,22,20]$, it is possible to recognize four major teachers' conceptions of evaluation and its impact on evaluative practice [17]:

- Evaluation as improvement. Teachers who view evaluation from this perspective consider that the information that emerges from the evaluation serves to change and improve their own teaching and student learning. These teachers use various strategies to evaluate students, providing them with quantitative and qualitative information for both teachers and students (18-20,3].

- Evaluation as school accountability. Teachers who evaluate based on these beliefs consider that evaluation serves to account for their own teaching work and the achievement of standards, as well as the educational contribution of the school in society. For these teachers, evaluation is the responsibility of the school and serves to demonstrate the quality of their teaching.

- Evaluation as accountability of the student himself. This conception holds that students are responsible for their own learning process. So, the teacher limits himself to accrediting and rating their academic achievement [24]. From this perspective, teachers should be the most "objective" possible in order to correctly grade their students as this has consequences such as graduation, selection or public reporting.

- Evaluation as an irrelevant process. Teachers who conceive the evaluation process from this perspective reject the evaluation as they consider it to be one more element of the teaching process. They consider that having to grade or value students affects their autonomy and professionalism as well as student learning. Furthermore, they consider that the data obtained from the evaluation are invalid and less reliable [18].

Remesal [5] constitutes a landmark both for its quality and for having been developed in our context. This researcher developed an ambitious investigation on the evaluation concepts of primary and secondary education teachers in Spain. The purpose of the study is to explore conceptions about the functions of teacher evaluation. In the qualitative study, in-depth interviews were conducted with thirty teachers. The evaluation concepts are analyzed based on the position of teachers in a pedagogical or social pole. Teachers with purely pedagogical conceptions consider evaluation as a regulatory element of student learning and their own practice. Those with purely social conceptions conceive the evaluation as a social accrediting element, which should not change the teaching process, considering teaching as something purely objective and rejecting the qualitative methods of evaluation. The results of the study show that $40 \%$ of the teachers conceive the evaluation in a mixed social way (that is, not purely social but closer to this pole than to the pedagogical one); $24 \%$ have a mixed pedagogical conception; $16 \%$ with a purely pedagogical conception and another $16 \%$ with a purely social conception. These data show that teachers continue to have entrenched traditional conceptions of evaluating student learning. 
Even knowing that context is a fundamental input for the elaboration of teachers' conceptions [18], there is not much research that allows knowing which contexts generate which conceptions [27]. However, the contributions of Prieto [14] stand out. This scholar considers that beliefs are deeply related to the context in which they are developed, so that the socioeconomic, cultural and linguistic level of the students and in the secondary schools will directly influence the conceptions and beliefs of teacher evaluation. According to her, the contents and the way to evaluate them are determined based on the context of the educational center. From this perspective, teachers located in more challenging or difficult contexts should adapt more to the differences between students, "such as the social and cultural diversity that characterizes them and therefore, evaluation becomes the path that determines their path school, based on the quality of its cultural capital [14]". Thus, the beliefs about students who come from the most vulnerable sectors are related to their lower capacity, their low endowment or their inevitable sociocultural and linguistic disadvantages.

\section{METHODOLOGY Method}

To reach the goal assigned to this research, phenomenography is used as a way of approaching teachers' conceptions [28-30]. Marton [29] described phenomenology as an empirically based approach that seeks to identify the limited number in qualitatively different ways of how different people experience, conceptualize, perceive, and understand various types of phenomena. It is characterized by being a method that changes continuously, since it is built together by those who participate in it.

Its object is the different (or similar) ways of how we are aware of the world, how we experience, understand, learn and see the various phenomena and situations in the world. From a phenomenographic perspective, the researcher's interest does not focus on the processes themselves but on how the subjects experience and perceive these processes [31].

\section{Research participants}

A fundamental question in relation to phenomenographic studies is the choice of participants for the research. The participants in this research are twenty-four EFL teachers selected from the twelve regions of the country at the rate of two secondary schools per region. Of the two schools selected per region, one is located in a purely rural area (Challenging context) and the second one in an urban area (Favorable context). Care was taken to select the secondary schools based on the socio-economic context. The said context was considered either favorable or challenging based on the socioeconomic level of the neighborhood where the school is located (rural or urban) and the families of the students who attend that center, and the social, cultural and linguistic characteristics of these students. Aggregated data per region made available in the report of the results of the fourth General Population Census of 2013 were taken into account.

\section{Research instrument}

The instrument used in the present study is the phenomenographic interview [32]. This method of obtaining information is based on self-reporting [29]. The key to carrying out a phenomenographic interview is to allow the participant to reflect on their experience of a phenomenon [33]. The experiences captured by the interview are made up jointly by the interviewer and the interviewee [29], understood as a conversation between two colleagues on a topic of mutual interest [33].

The phenomenographic interview is semistructured in nature with only a few predetermined key questions [29, 11, 31]. This does not mean that the phenomenographic interview has no focus since the object of study is the focus of the interviewer at all times and guides the interview at all times.

To respond to this need for a semi-structured interview, the interviews started from three generating questions:

- How do you evaluate?

- How do you conceive your evaluation? And

- How would your ideal evaluation be?

From June 2019 to September 2019, data were collected, recorded and subsequently transcribed using Voice Notes ${ }^{\mathrm{TM}}$ v.3.56 (free) set up on hiOS android TECNO-F2 cellphone.

In accordance with the phenomenographic method, a criterion of proximity to the participants' discourse has been followed. The researcher tries to be neutral to the ideas of the study participants, analyzing the data obtained with an open mind and without any participation from their perspectives [34]. It was recorded by noting the presence of conceptualizations belonging to certain categories and sub-categories in the teachers' discourse, separating the teachers who work in schools with favorable socio-economic context from those in challenging contexts. Leedy and Ormrod [35] emphasize that there is usually no single "right" way to analyze the data in a qualitative study. In this line, the search for categories led me to find an element those groups and characterizes the different conceptions of teachers: the notion of fair evaluation. In this way it was used to bring together the differences in their conceptions.

\section{FINDINGS}

The findings of the present study show a complex and nuanced vision that allows understanding teachers' conceptions of their evaluative practice. From the phenomenological interviews carried out, and from their analysis, a series of differences appear in their 
conceptions of their own practice and of an evaluation. These differences generate the concept of fair evaluation as a characterizing and unifying element of them. That is why the findings are organized in two sections: the conceptions about their evaluative practices and their conception of what is a fair evaluation.

- Participants' conceptions about their own evaluative practices

Do EFL teachers in secondary schools located in socio-economically favorable contexts have different conceptions of their own evaluative practice from EFL teachers in secondary schools in challenging contexts? This is the research question that guides this section. And the answer to it is a yes, but a yes with infinite nuances.

A first striking element is related to sources that teachers are inspired to take the tests. In schools in favorable contexts, it is very common to use external references, essentially the textbook as a minimum base and, from there, raise the level more with those worked in the classroom. Let's see it with three examples from three teachers from different schools:

Kokou (from a favorable context (FC)): To elaborate the test I rely on the textbook; well they have a textbook. [...] I ask them a little bit of that than what we have seen in class.

Dossi (FC): I had it prepared part of last year, but I never give everything the same, that is, certain things I have to change because maybe some type of information because I have seen that I have not given it so well or I have seen that they do not or they have been able to capture so well and then I do not insist so much on this [...]. So, in addition to relying on the textbook, there is now great material for teachers. We have extension material, we have reinforcement material, and I use that for exams.

Alain (FC): There are questions that have been worked on in class with the book as well as other questions that have arisen in class, for example, from this control, which was a sheet that does not appear on the subject of the book, but we did work in class.

The teachers of schools in challenging contexts, however, their sources are more internal, more self-referential than external. In their speeches they constantly appear the elaboration through teamwork and collaboration with other teachers of that course to determine the minimum content or skills as far as they want their students to go; curiously none of them named the textbook. As Richard and Paul comment:

Richard (from a Challenging context (CC)): I coordinate the evaluation tests with my colleagues and we elaborated everything together. In other words, the exams.

Paul (CC): The exams are usually done by me and often in teams, in collaboration, and I usually do exams that are very varied and very different from each other.

Although practically all teachers claim to use a wide variety of instruments for obtaining information for assessment (attitude scales, observation sheets, class diaries ...), the written exam, with questions of different types, is still as much the test most teachers claim to use. Even with this general pattern, some differences are observed depending on the favorable-challenging context in which the secondary schools are located.

Indeed, the information points to the fact that teacher who works in centers whose context is favorable use quantitative tests more frequently and with more weight. The conception they have is that this type of tests are more objective and make it possible to have clearer information for students to improve their learning. Illustrating this idea, Agossou and Noudagba affirm:

Agossou (CC): I use two exams per semester. Another assessment test is the review of the class workbook, but that only serves to round the grade. The weight of the note has the written exams they take on the subjects.

Noudagba (FC): If I have to be honest, it is that; the assessment instruments above all are: exams as I am telling you, those oral tests, small expositions or sometimes I tell them, as they still do not have the ability to speak [...] and there I evaluate them and note their participation and so on [...] but what matters most is the exam.

School teachers in challenging contexts, even using the traditional written exam, are more interested in the use of "alternative" tests, which do not show only the students' ability to memorize and write. Their concern is that the different skills and abilities of their students, the students' actual learning and the effort they make must also be considered. Three extracts serve to illustrate:

Gnon (CC): Apart from the written control, I also evaluate the oral expression, I do not control the oral expression in one day, which happens in class activities continually one day they have to expose some, another day they have to expose others, I have my observation sheet that without saying to them "I am evaluating you" but I do put how they are doing it, with the date and so on other days I am asking them [...] Another separate thing is what I point in my diary of something that has caught my attention the most [...] Written controls count $50 \%$ of the mark in my 
evaluation, the other $50 \%$ are other types of competences that I consider essential and that cannot be measured with a exam.

N'tcha (CC): For me the most important thing is the daily life of the boys and their learning process, that they are aware. For this reason, the work plan has a 60 percent of the total percentage of the note.

Assou (CC): ... I don't usually take exams as such, I see it in a way to give a child a grade but their abilities are not so well demonstrated... [...] I try to do evaluation exercises where they don't realize that they are being evaluated and not as a real test, so it motivates them to do it in a much more appropriate way $\cdots$

Closely related to the previous element is the fact that teachers in challenging contexts show a special concern to adapt the tests to situations with which students can feel identified. Some words that reflect this approach are the following:

Robert (CC): In a test, for example, I wrote as a reading of some children who were from another neighborhood and who went to a school in the afternoon and such, that they were not them but good for them to feel that way, more motivated and such. And of course, it turned out quite well, with that they stayed immediately. [p4DES: 2]

Teachers in challenging contexts insist that assessment be individualized, tailored to the needs and characteristics of students. The ratio per classroom, common school evaluations, the time they have or the administration are some of the reasons indicated by teachers that make it more difficult to achieve a true individual and adjusted evaluation for each student. In the words of the teachers themselves:

Hessou (FC): Tailor the tests more to each student, because it really is very difficult to do a written exam, for example, a written control for all the same because it is very difficult. You go to the average, [...] but there are students that for them are very easy and for others very difficult, and in the end, it is not the same control.

Nina (CC): For me an ideal evaluation would be an individualized evaluation, taking into account everything that surrounds the student, their involvement, their effort ... as I was saying, not only the objective test, like an exam. It is that each child is a world, each child, each family behind, so that, value all that.

Talia (CC): I take into account the needs of the student, their abilities, everything, even their environment, I take into account their family situation, everything. I believe that to evaluate a student and especially at an elementary stage and when they are younger, it is necessary to take into account not only the knowledge they have acquired, which is super important, but also everything around them.

It is also observed that, compared to those who teach in favored schools, teachers from challenging schools determine that it is essential to focus evaluation towards a more qualitative process. The teachers consider that the written tests do not offer real information about the students' learning, and that it is necessary to know more qualitative assessment instruments and carry them out, to promote a more continuous process of monitoring the students, being able to give them more feedback, frequently and focused on the needs of each student. This is how Assiba and Fifa express it:

Assiba (CC): And in some other way that I would like to be more oral, more individual, I would need an hour for each student [...] you would have to do the most open and not so closed exams, not with such closed answers... I think that I could make them a little more open ... that, that I could adapt them more to the level of each specific and well, the objective would be that there were no written tests.

Fifa (CC): And then it seems more fair to me when there are different types of questions or different ways of demonstrating what you know ... I don't like exams ... only exams, I don't like them ... but I like that ... students ... learn to demonstrate what they know putting it into practice and giving it to others.

Finally, teachers in challenging schools consider the need for evaluation to be a constant process and to be repeated, giving students different opportunities to demonstrate their knowledge and learning. Fifa expresses it in the following way:

It is also fair that opportunities are given, that more than one opportunity is given because... there cannot be a single opportunity that is not fair, because you can have a bad day, because you can....

Linked to this idea of ndividualization or not of evaluations, teachers from favored schools assume that the return of the results is done in a group way, thus they consider that the process is more transparent. Sadognon indicates that:

I correct the exam first, what happens is that I always want them to correct it and make an attempt to find out what they did wrong and such, so I do dedicate a class for that. [...]. What I usually do is give them the control, first we correct it in a group way to solve the doubts. Actually what I do to them is, I give them the control, in it comes the note and a comment about what I found their control and how it can improve, what mistakes it has had... 
and then I make a group correction [...]. In this group correction they ask "why is this wrong or ...?", Yes, they usually ask little things.

Teachers from challenging contexts, for their part, are concerned that such devolution be as individualized as possible. The underlying idea is the need for students to improve their learning with clear guidelines:

Fina (CC): ... what I do to them is, I give them the control, in it comes the note and a comment about what I found their control and how it can improve, what mistakes it has had ... and then I make a group correction.

Along these same lines, Miwoto, teaching in a challenging context, states that:

If I can with everyone I comment individually one by one. And if not, each one has a signal ... it does not mean bad, except for the typical end-of-term tests, the others I do not think is wrong or nothing, for example if there is a misspelling, if it is an expression that is not well done or If it is something in which they have been mistaken that this is not the reading, well then I put them like a little arrow and they already know that there they have to observe that something happens. And then it is commented out loud.

\section{- The notion of fair evaluation?}

It is possible to configure the teachers' conception of what a just evaluation is for students. While for teachers in favorable schools, this concept is linked to impartiality, to the idea of an objective evaluation, the same for everyone; for those in challenging contexts, it is more related to the idea of valuing the effort of each student; hence also the importance of individual adaptation of evaluations.

Indeed, for those with favorable contexts, the best test is one that has no margin for error. In other words, it is absolutely closed and does not admit discussion or debate. In this line, Agbonnon (from a favorable school) states that:

What I am looking for is objectivity [...]. I correct as objectively as possible. Look, the true and false is very easy, 5 items by 2 points. [...] I like it in such a way that it is structured and that they know... in general I don't usually have protests like "and why do you put me here 1.25 over 2?" and I say "let's see, how many causes were there?" and indeed ... spelling and expression, that goes apart. I correct the 5, or whatever questions there are, if any question is worth less, it also appears in the exam.
Objectivity and transparency are two criteria that a fair evaluation must have for teachers in favored contexts:

Désiré (FC): Many times ... I would use more complementary activities and I would use other types of work more ... but objectivity prevails.

Kodjo (FC): I think that an important component of justice is honesty, so I think that there must be clarity in the evaluation and know what to expect. Having established criteria and based on those criteria, the students being evaluated know that they are going to be evaluated and know what the evaluation is for.

Kloufon (FC): There is a problem that is the objectives... you have to stick to some objectives set by the school authorities, and it is assumed that if the child does not reach those objectives because he cannot pass 10 out of 20, it is assumed... he cannot pass in that evaluation

Lima (FC): An evaluation that takes into account the entire environment of the student, all its characteristics, its evolution, the process it has had.

The teachers who teach in schools located in challenging environments, meanwhile, give more importance to the evolution of the student, to the real progress of students between test and assessment test:

Carole (CC): I do not correct closedly. So what I am trying to assess is that there has been an apprenticeship, that there has been progress and ... that there is a half of short tests ... it is to try to pass them.

Gbodja (CC): The important thing is not the grade they get in the written exam, but to know where they started and how far they have gone. It cannot be the same as a learner who starts with a note of 8 and reaches 9.5, and another who starts with a 2 and reaches 9. In the first case it seems that your contribution has been very little, while in the second case, the achievement must be recognized. The note you take from an exam doesn't tell me much, it doesn't worry me, it only detects my needs. What I try to value throughout the year is the effort and progress they have had from their starting point to their end point.

Also, one aspect that school teachers highlight in challenging contexts is being able to truly assess student effort. Many teachers indicate the difficulty of knowing how hard a student works, but they emphasize the importance of rewarding those who put more effort into the task. Thus, teachers state that: 
Bina (CC): In a fair evaluation it would be necessary to value a person much more than it cost him from the first moment to acquire that knowledge and he has fought it, he has fought it and he has managed to acquire that knowledge ... that is to say for me he cannot have the same note the child who has removed the same five operations that from the first moment take them phenomenal, as the child who has taken a month to reach them. Because maybe the one that has come out from the phenomenal moment first, could have come one step higher...

Rian (CC): You always have to keep learning. I'm learning to evaluate efforts, rather than the grade itself. Give importance to daily work, daily effort, and see where they start from and how far they go.

Bertine (CC): Look at an ideal evaluation would be that evaluation that reflects the child's effort during those 15, 20 days or a year ... if you want to evaluate specific content or a subject that you are able to assess the effort that the child has made.

Messe (CC): The one that really measures the effort and if that effort has led to achieving the objectives that I have set, taking into account where the student starts and where he has arrived, especially taking into account where he starts from. Because it is not the question to arrive at the same point but to see, that is, the one that evaluates the amount of road that you have made related to your effort.

What is a fair evaluation? The one that is objective, transparent and egalitarian or the one that is objective, differentiating and that measures progress more than what has been achieved? Teachers' conceptions of this issue depend on the context in which their work is carried out. From there, it can be deduced that their evaluative practices are also different.

\section{DISCUSSION}

This research has attempted to collect empirical evidence to state that the socio-economic context in which the teaching action takes place determines the evaluative conceptions of the teachers. Differences have been found in the concepts regarding the evaluation references, about the tests used and their adaptation, about the return of information. All this to get to configure a radically different conception of fair evaluation in one group of teachers and in another.

If these results are related to the two major evaluation concepts, the most "pedagogical" and the most "social", there is a tendency to have teachers in favorable contexts who are more social and those in challenging contexts who are more pedagogical. Evidence of the great leap between wishes and reality has also been provided, at least in the evaluation of the students, as found by Winterbottom et al. [25]. Indeed, all teachers stated that their actual evaluative practice is far from what they consider to be an optimal evaluation of student learning.

However, the most suggestive aspect of this study is the appearance of the concept of fair evaluation and how it is seen differently by teachers in favorable and challenging contexts. The notion of justice, understood as fairness or equity, is one of the most important topics and has attracted many researchers [36, 37], although, on many occasions, it is associated with the quality of the tests and their construction. Further studies need to be carried out on its different nuances.

\section{CONCLUSION}

The results of this study are expected to contribute to improve teaching practices. By knowing and understanding how these conceptions are and how they are constructed, it is possible to modify them. However, this research has shown that teachers' conceptions, on many occasions, have much more common sense and educational value than the inconsistent administrative obsessions.

This study has opened an interesting line of research related to the incidence of the socio-economic context on the conceptions of teachers. As it states, the context determines the conceptions and, with it, the evaluative practices of teachers and the subsequent development of students. Thus, in the face of the supposed undifferentiated treatment by school administrations, the research shows that school segregation configures very different teachings depending on the socio-economic context. If the idea that greater support is needed for the student who needs it most, there is no reason not to extrapolate this idea to schools.

Finally, this research has shown that the conceptions of teachers working in challenging contexts have elements of a more inclusive evaluation, more adapted to all students, while teachers from schools in more favorable settings are more demanding, seeking more excellence. Trying to qualify one conception superior to the other is as wrong as thinking that this adaptation to the context is intrinsically positive. In the end, it is the context that is determining the type of evaluation and teaching and with it the future of boys and girls.

\section{REFFERENCE}

1. Coll, C., \& Remesal, A. (2009). Conceptions of mathematics teachers about the functions of learning assessment in compulsory education. Childhood and Learning, 32(3), 391-404.

2. Griffiths, T., Gore, J., \& Ladwig, J. (2006). Teachers' fundamental beliefs, commitment to reform and the quality of pedagogy. Annual Conference of the Australian Association for 
Educational Research. Adelaide University, Australia.

3. Black, P., Harrison, C., Lee, C., Marshall, B., and William, D. (2002) .Working inside the black box: Assessment for learning in the classroom. London: Department of Education and Professional Studies, Kings College.

4. Pope, N., Green, S. K., Johnson, R. L., \& Mitchell, M. (2009). Examining teacher ethical dilemmas in classroom assessment. Teaching and Teacher Education, 25, 470-483.

5. Remesal, A. (2011). Primary and secondary teachers 'conceptions of assessment: A qualitative study. Teaching and Teacher Education, 27(2), 472-482.

6. Murillo, F.J., and Hidalgo, N. (2014). Fair evaluation: between equality and equity. Iberoamerican Journal of Educational Evaluation, 7(3), 5-6.

7. Marshall, B., \& Drummond, M.J. (2006). How teachers engage with assessment for learning: Lessons from the classroom. Research Papers in Education, 21(2), 133-49.

8. Lupton, R. (2005). Social justice and school improvement: improving the quality of schooling in the poorest neighborhoods. British Educational Research Journal, 31(5), 589-604.

9. Pajares, M.F. (1992). Teachers' Beliefs and Educational Research: Cleaning Up a Messy Construct. Review of Educational Research, 62(3), 307-332.

10. Van den Berg, R. (2002). Teachers 'meanings regarding educational practice. Review of Educational Research, 72(4), 577-625.

11. Marton, F. (1986). Phenomenography: A research approach to investigating different understandings of reality. Journal of Thought, 21(3), 28-49.

12. Pratt, D.D. (1992) .Conceptions of teaching.Adult Education Quarterly, 42(4), 203-220.

13. Thompson, A.G. (1992). Teachers' beliefs and conceptions: A synthesis of the research. In D.A. Grouws (Ed.), Handbook of research on mathematics teaching and learning (pp. 127-146). New York: Macmillan.

14. Prieto, M. (2008). Teachers' beliefs about Evaluation and Incidental Effects. Pedagogy Magazine, 29(84), 123-144.

15. Fives, H., \& Gill, M.G. (2014). International Handbook of Research on Teachers 'Beliefs. London: Routledge.

16. Atjonen, P. (2014). Teachers 'views of their assessment practice. The Curriculum Journal, 25 (2), 238-259.

17. Azis, A. (2012). Teachers 'conceptions and use of assessment in student learning. Indonesian Journal of Applied Linguistics (IJAL), 2(1), 40-52.

18. Brown, G.T.L. (2003). Teachers 'conceptions of assessment. Auckland: University of Auckland.

19. Brown, G.T.L. (2004). Teachers' conceptions of assessment: implications for policy and professional development. Assessment in Education: Principles, Policy \& Practice, 11 (3), 301-318.

20. Brown, G.T.L., \& Hirschfeld, G.H. (2008). Students 'conceptions of assessment: Links to outcomes. Assessment in Education: Principles, Policy \& Practice, 15(1), 3-17.

21. Brown, G.T.L., \& Remesal, A. (2012). Prospective Teachers' Conceptions of Assessment: A CrossCultural Comparison. The Spanish journal of psychology, 15 (1), 75-89.

22. Brown, G.T.L., Lake, R., \& Matters, G. (2011). Queensland teachers 'conceptions of assessment: The impact of policy priorities on teacher attitudes. Teaching and Teacher Education, 27 (1), 210-220.

23. Chen, J., Brown, G. T., Hattie, J. A., \& Millward, P. (2012). Teachers' conceptions of excellent teaching and its relationships to self-reported teaching practices. Teaching and teacher education, 28(7), 936-947.

24. Harris, L. R., \& Brown, G. T. (2009). The complexity of teachers' conceptions of assessment: Tensions between the needs of schools and students. Assessment in Education: Principles, Policy \& Practice, 16(3), 365-381.

25. Winterbottom, M., Brindley, S., Taber, K. S., Fisher, L. G., Finney, J., \& Riga, F. (2008). Conceptions of assessment: trainee teachers' practice and values. The Curriculum Journal, 19(3), 193-213.

26. Prieto, M., \& Contreras, G. (2008). The concepts that guide the evaluative practices of teachers: a problem to uncover. Pedagogical Studies, 34(2), 245-262.

27. Rubie-Davies, C.M. Flint, A., \& McDonald, L.G. (2012). Teacher beliefs, teacher characteristics, and school contextual factors: What are the relationships? British Journal of Educational Psychology, 82(2), 270-288.

28. Bouden, J.A., \& Walsh, E. (2000) .Phenomenography. Victoria: Royal Melbourne Institute of Technology University Press.

29. Marton, F., \& Booth, S. (1997). Learning and Awareness. New York: Lawrence Erlbaum.

30. Richardson, J. I. (1999). A history of Australian travel and tourism. Hospitality Press.

31. Reed, B. (2006). Phenomenography as a way to research the understanding by students of technical concepts. Technological Innovation and Sustainability, 1, 1-11.

32. Trigwell, K. (2000). A phenomenographic interview on phenomenography. In J. A. Bowden and E. Walsh (Eds.), Phenomenography (pp. 6282). Victory: RMIT.

33. Kvale, S. (1996) Interviews: an introduction to qualitative research interviewing. Thousand Oaks, CA: SagePublications.

34. Orgill, M.K. (2002). Phenomenography. Recovered from 
http://chemed.chem.purdue.edu/chemed/bodnergro up/frmaeworks/phenomenography.htm

35. Leedy, P., \& Ormrod, J. (2001). Practical research. Upper Saddle River, NJ: Merrill.

36. Gipps, C., \& Stobart, G. (2009) .Fairness in assessment. In C. Wyatt-Smith and J. Cumming (Eds.), Educational assessment in the 21st century:
Connecting theory and practice (pp. 105-118). Dordrecht: Springer.

37. Pettifor, J.L., \& Saklofske, D. H. (2012) .Fair and ethical student assessment practices. In C.F. Webber and J. Lupart (Eds.), Leading student assessment (pp. 87-106). Dordrecht: Springer. 